\title{
O IMPOSTO DE RENDA E OS PRINCÍPIOS DA GENERALIDADE, DA UNIVERSALIDADE E DA PROGRESSIVIDADE
}

Orinetador: Professor Doutor Gerd Willi RothMANN

UNIVERSIDADE DE SÃO PAULO

FACULDADE DE DIREITO SÃO PAULO

2009 


\section{O IMPOSTO DE RENDA E OS PRINCÍPIOS DA GENERALIDADE, DA UNIVERSALIDADE E DA PROGRESSIVIDADE}

Tese apresentada à Faculdade de Direito da Universidade de São Paulo como parte dos requisitos para a obtenção do título de Doutor, sob a orientação do Professor Doutor Gerd Willi Rothmann

UNIVERSIDADE DE SÃO PAULO

FACULDADE DE DIREITO

SÃO PAULO

2009 


\section{RESUMO}

Nesta obra, o autor discorre sobre o imposto de renda e os princípios constitucionais da generalidade, da universalidade e da progressividade.

A Constituição Federal estruturou o imposto de renda como imposto pessoal, geral, universal e progressivo, características que devem ser conjugadas com os demais princípios constitucionais, a que este tributo também deve obediência.

Diversos temas são abordados ao longo do trabalho, tais como os princípios constitucionais e a sua importância na interpretação e na aplicação das leis tributárias; a diferença entre princípios e regras; a estrutura do imposto de renda na Constituição Federal e no Código Tributário Nacional; o princípio da igualdade e o princípio da capacidade contributiva.

Além disso, são analisados, com maior abrangência e profundidade, os princípios da generalidade, da universalidade e da progressividade.

Estes três princípios devem, segundo a nossa Constituição Federal, informar o imposto sobre a renda e proventos de qualquer natureza. Portanto, como princípios constitucionais, especificamente aplicáveis ao imposto de renda, são o fundamento não só para a criação legislativa dos direitos e das obrigações tributárias referentes ao aludido imposto, como também para a sua interpretação e a sua aplicação.

Aprofundando o estudo da legislação ordinária, o autor conclui que, em diversos aspectos, o legislador não observa os princípios constitucionais que devem reger a tributação pelo imposto de renda ao instituir concretamente os fatos geradores deste imposto.

Palavras-chave: Imposto de Renda, Princípios Constitucionais, Generalidade, Universalidade, Progressividade. 


\section{ABSTRACT}

In this paper, the author discusses the income tax and the constitutional principles of generality, universality and progressivity.

The Federal Constitution structured the income tax as a personal, general, universal and progressive tax, characteristics which must be integrated with further constitutional principles, to which this duty is also subjected.

Throughout the discussion several issues are approached, such as the constitutional principles and its importance in the interpretation and application of tax laws; the difference between principles and rules; the structure of the income tax in the Federal Constitution and in the National Tax Code; the principle of equality and the principle of the power to contribute.

In addition, the principles of generality, universality and progressivity are analyzed in dept and more comprehensively.

According to our Federal Constitution, these three principles must inform the tax regarding the income and earnings of any nature. Therefore, as constitutional principles, specifically applicable to the income tax, they constitute the ground not only to the legislative creation of tax rights and obligations regarding said tax, but also to its interpretation and application.

Deepening the study of the ordinary legislation, the author concludes that, in several aspects, the legislator does not observe the constitutional principles which must govern the application of the income tax when the generating factors of said tax are concretely established.

Key words: Income Tax, Constitucional Principles, Generality, Universality, Progressivity. 


\section{RÉSUMÉ}

Dans cet ouvrage l'auteur discourt sur l'impôt sur le revenu et les principes constitutionnels de la généralité, de l'universalité et de la progressivité.

La Constitution Fédérale a structuré l'impôt sur le revenu comme étant un impôt personnel, général, universel et progressif, caractéristiques qui doivent être conjuguées avec les autres principes constitutionnels auxquels ce tribut doit également obéissance.

Plusieurs thèmes sont abordés tout au long du travail, tels que les principes constitutionnels et leur importance dans l'interprétation et dans l'application des lois fiscales; la différence entre principes et règles; la structure de l'impôt sur le revenu selon la Constitution Fédérale et selon le Code National des Impôts; le principe de l'égalité et le principe de la capacité contributive.

Par ailleurs sont analysés, avec une plus grande étendue et profondeur, les principes de la généralité, de l'universalité et de la progressivité.

Ces trois principes doivent, selon notre Constitution Fédérale, gouverner l'impôt sur le revenu et les rentes de toute nature. Par conséquent, comme principes constitutionnels, applicables spécifiquement à l'impôt sur le revenu, ils constituent le fondement non seulement de la création législative des droits et des obligations fiscales relatives à l'impôt cité, mais également de leur interprétation et de leur application.

Approfondissant l'étude de la législation ordinaire, l'auteur conclut que, sous divers aspects, le législateur n'observe pas les principes constitutionnels qui doivent régir la taxation selon l'impôt sur le revenu en instituant concrètement les faits générateurs de cet impôt.

Mots Clé: Impôt sur le revenu, Principes Constitutionnels, Généralité, Universalité, Progressivité. 


\section{SUMÁRIO}

INTRODUÇÃO

1. OS PRINCÍPIOS CONSTITUCIONAIS E A INTERPRETAÇÃO E APLICAÇÃO DAS LEIS TRIBUTÁRIAS

3. A ESTRUTURA DO IMPOSTO DE RENDA NA CONSTITUIÇÃO FEDERAL E

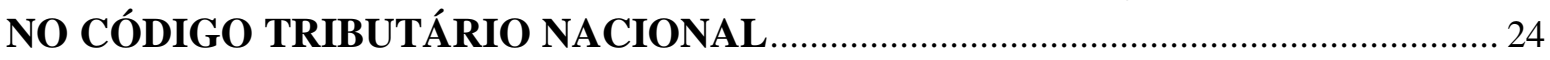

3.1. O Objeto do Imposto de Renda na Constituição.................................................................... 24

3.2. Configuração do Imposto de Renda no Código Tributário Nacional........................................ 26

3.3. Aquisição da Disponibilidade Econômica ou Jurídica de Renda ou Proventos de Qualquer Natureza

5. A IGUALDADE E OS PRINCÍPIOS DA CIÊNCIA DAS FINANÇAS .............................. 51

6. PRINCÍPIO DA CAPACIDADE CONTRIBUTIVA ………………………………….......56

7. PRINCÍPIO DE VEDAÇÃO DO CONFISCO....................................................................... 66

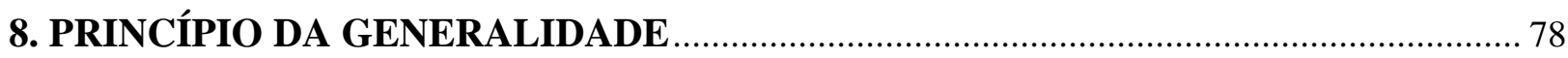

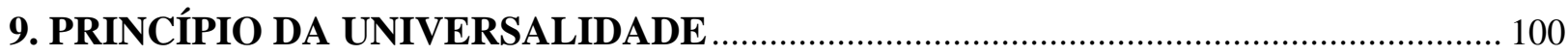

9.1. Tributação Definitiva ou Exclusiva na Fonte pelo Imposto de Renda ....................................... 109

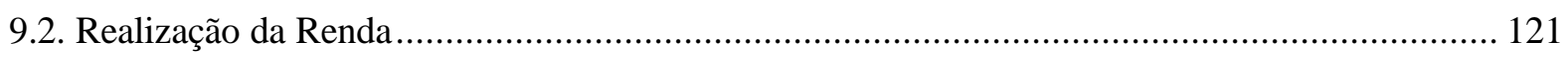

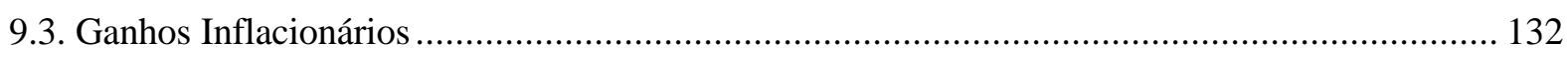

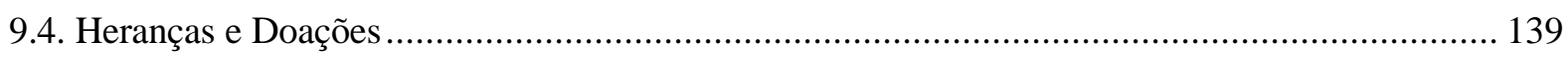

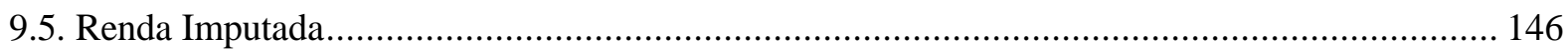

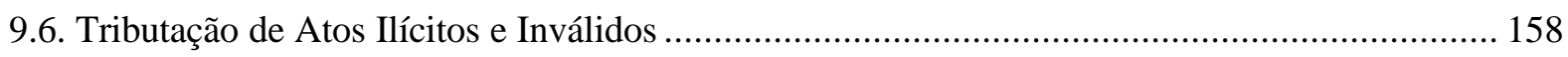

10. A PROGRESSIVIDADE NO IMPOSTO DE RENDA ……………………………….... 165

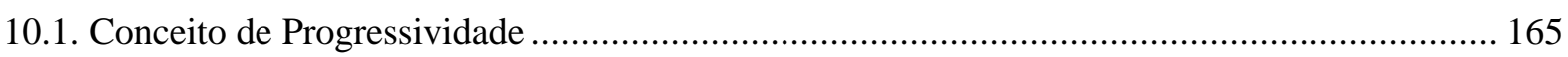

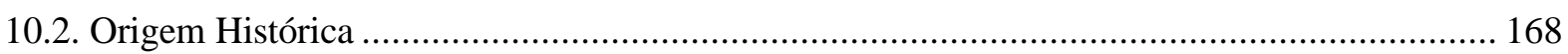

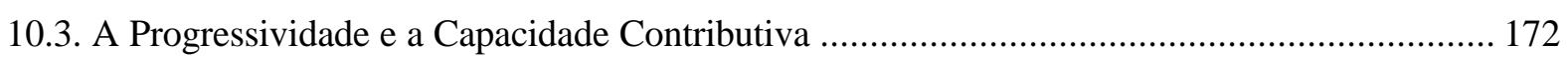

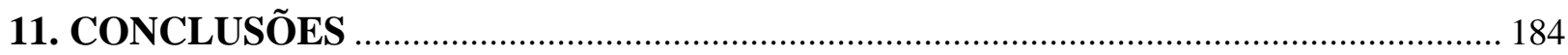

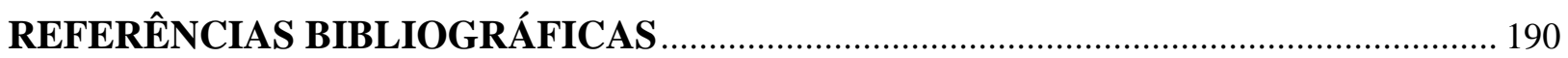




\section{INTRODUÇÃO}

Em nosso trabalho, pretendemos discorrer sobre o imposto de renda e os princípios da generalidade, da universalidade e da progressividade. Apesar de a Constituição Federal, em seu art. $153, \S 2^{\circ}$, I, mencionar que o imposto de renda "será informado pelos critérios da generalidade, da universalidade e da progressividade", filiamo-nos à corrente que entende estarmos diante de verdadeiros princípios tributários e não somente de critérios a serem utilizados na tributação pelo imposto de renda.

Com efeito, a Constituição estruturou o imposto de renda como imposto pessoal, geral, universal e progressivo, características que devem ser conjugadas com os demais princípios constitucionais, a que este tributo também deve obediência. Assim, é fundamental a análise da influência dos princípios da generalidade, da universalidade e da progressividade na estruturação do imposto de renda.

Estes três princípios devem, segundo a nossa Constituição Federal, informar o imposto sobre a renda e proventos de qualquer natureza. Portanto, como princípios constitucionais, especificamente aplicáveis ao imposto de renda, são o fundamento não só para a criação legislativa dos direitos e das obrigações tributárias referentes ao aludido imposto, como para a sua interpretação e a sua aplicação.

Destarte, é de fundamental importância que o legislador, ao elaborar as leis que dispõem sobre o imposto de renda, observe os princípios acima referidos, sob pena de editar leis inconstitucionais.

É importante salientar que a norma do inciso I do parágrafo $2^{\circ}$ do art. 153 da Constituição Federal não constava nas Constituições anteriores à de 1988. Daí a fundamental importância dessa norma, que importou em uma inovação da ordem jurídica preexistente à entrada em vigor da Constituição Federal de 1988.

Por outro lado, podemos observar, compulsando a legislação do imposto de renda, que, em diversos aspectos, o legislador ordinário não observa os princípios da generalidade, da universalidade e da progressividade, como será analisado com maior profundidade no decorrer desse trabalho. 
Pelo exposto, entendemos ser fundamental um estudo mais aprofundado destes princípios que, conforme expressa determinação de nossa Lei Fundamental, devem informar a tributação pelo imposto sobre a renda e proventos de qualquer natureza. 


\section{CONCLUSÕES}

Para a criação, a interpretação e a aplicação das leis tributárias deve-se partir das regras e princípios constitucionais, pois a eles se subordinam todas as leis existentes no País.

O Brasil possui a mais detalhada Constituição do mundo no que se refere à disciplina tributária. Inúmeros são os princípios e as regras explícitos ou implícitos em nossa Constituição Federal, que delimitam ou mesmo vedam o poder de tributar.

Os princípios constitucionais tributários constituem expressão dos direitos individuais dos contribuintes em face do Poder Público, no sentido de limitar a sua competência tributária.

Como princípios constitucionais especificamente aplicáveis ao imposto de renda, os princípios da generalidade, da universalidade e de progressividade são o fundamento não só para a criação legislativa dos direitos e das obrigações tributárias referentes ao aludido imposto, como para a sua interpretação e a sua aplicação.

Do ponto de vista jurídico, o principal traço distintivo da Constituição é justamente a sua supremacia, a sua posição hierárquica superior à das demais normas do ordenamento jurídico. Por isso, as leis, atos normativos e atos jurídicos em geral não poderão existir validamente se incompatíveis com alguma norma constitucional.

Não há norma constitucional que seja destituída de eficácia. Todas elas irradiam efeitos jurídicos, importando sempre uma inovação da ordem jurídica preexistente à entrada em vigor da Constituição.

As normas constitucionais têm aplicação obrigatória, devendo ser acatadas tanto pelo legislador, ao elaborar as leis, como pelos juízes, ao exercer o controle de constitucionalidade das leis.

É o caso da norma do inciso I do parágrafo $2^{\circ}$ do art. 153 da Constituição Federal, que prevê que o imposto de renda será informado pelos princípios da generalidade, da universalidade e da progressividade. 
Nas Constituições anteriores à de 1988 não constava norma semelhante. Daí sua fundamental importância, pois implicou em uma importante inovação da ordem jurídica preexistente à entrada em vigor da Constituição Federal de 1988.

O objeto do imposto de renda, contido na discriminação de rendas tributárias, é a "renda e proventos de qualquer natureza". Esta é a realidade econômica que pode ser gravada pelo aludido imposto.

A determinação do objeto do imposto de renda não é suficiente para a criação do imposto e sua exigência, pois existem divergências doutrinárias quanto ao conceito de "renda e proventos de qualquer natureza".

O imposto de renda é, conforme a mais abalizada doutrina e jurisprudência, exemplo de tributo que incide sobre uma materialidade não definida pelo direito privado e que, portanto, comporta um certo grau de indeterminação.

Por conseguinte, o significado mínimo do termo renda deve ser construído pela doutrina e a jurisprudência.

É mister a elaboração de um conceito jurídico, especificamente tributário de renda, capaz de dar segurança jurídica aos destinatários das normas que disciplinam a incidência do imposto de renda, já que não existe nenhuma definição absoluta e única do que seja renda tributável.

Em face da Constituição (art. 146, III, “a”), as normas gerais de direito tributário devem definir o fato gerador, a base de cálculo e o contribuinte dos impostos, de forma a impedir que o legislador ordinário crie hipóteses de incidência incompatíveis com o objeto dos impostos previstos no texto constitucional.

Ao entrar em vigor o novo sistema tributário nacional, a Constituição já encontrou no Código Tributário Nacional uma lei complementar. A Lei $\mathrm{n}^{\mathrm{o}}$ 5.172, de 25.10.1966, denominada Código Tributário Nacional, dispôs sobre o Sistema Tributário Nacional e instituiu normas gerais de direito tributário aplicáveis à União, Estados e Municípios, definindo o fato gerador do imposto de renda.

Dessa forma, em nosso país, o conceito jurídico de renda foi dado pelo Código Tributário Nacional, reconhecido como lei complementar de normas gerais em matéria de legislação tributária. 
O fato juridicamente hábil a gerar a incidência do imposto de renda, segundo o art. 43 do Código Tributário Nacional, é o acréscimo patrimonial experimentado pelo contribuinte ao adquirir uma riqueza nova.

Esse acréscimo patrimonial pode ser originado do capital aplicado ou da produção de trabalho do contribuinte, caso em que o produto auferido é conceituado como renda (art. 43, I, do Código Tributário Nacional), ou pode ser derivado de qualquer outra origem, e a ele se dá o nome de provento de qualquer natureza (art. 43, II, do Código Tributário Nacional).

Pode-se inferir que a aquisição da disponibilidade da renda, a que faz menção o art. 43 do Código Tributário Nacional, em terminologia e sistemática jurídica escorreita, nada mais é do que a aquisição de um direito. $\mathrm{O}$ fato gerador do imposto de renda ocorre, dessa forma, quando houver a aquisição de um direito real ou pessoal que acresça o patrimônio do indivíduo.

Se o direito adquirido pelo contribuinte tiver por objeto uma renda já recebida, teremos o acréscimo de um direito real ao patrimônio do contribuinte; se, por outro lado, o direito adquirido tiver por objeto uma renda que só será percebida no futuro, teremos um direito pessoal ou de crédito. Em ambos os casos, contudo, ocorrerá um acréscimo do patrimônio do contribuinte, pois a ele se agregarão novos direitos.

A Constituição determina, como princípio geral de tributação, o caráter pessoal dos impostos e sua graduação segundo a capacidade econômica do contribuinte $\left(\S 1^{\mathrm{o}}\right.$ do art. 145), vedando o tratamento desigual entre os que se encontrem em situação equivalente, bem como qualquer distinção em razão de sua atividade, independentemente da denominação jurídica dos rendimentos, títulos e direitos (art. 150, II).

De outra parte, a Lei Maior estabelece que o imposto de renda seja informado, nos termos da lei, pelos princípios da generalidade, universalidade e progressividade (art. 153, $\left.\S 2^{\circ}, \mathrm{I}\right)$, decorrentes do princípio da isonomia tributária (art. 150, inc. II).

De acordo com tais princípios constitucionais, o imposto de renda deverá incidir sobre todas as espécies de rendas e proventos (universalidade), obtidas por toda e qualquer pessoa (generalidade), de forma mais onerosa quanto maior o valor auferido (progressividade). 
Infere-se que o legislador constitucional previu um conjunto de princípios que se interligam, formando uma rede de proteção dos direitos fundamentais do contribuinte, limitadora do poder estatal de tributar.

O fato gerador do imposto de renda é a aquisição da disponibilidade econômica ou jurídica de renda ou proventos (acréscimos patrimoniais), ou seja, é o acréscimo verificado no patrimônio de uma determinada pessoa (física ou jurídica) num determinado período de tempo.

Embora a lei ordinária possa estabelecer o regramento do tributo, no que concerne à materialidade da hipótese de incidência, não pode a norma impositiva distanciar-se da matriz constitucional da exação, nem da realidade dos fatos do mundo fenomênico. Nesse sentido, ilegítima a pretensão de tributar acréscimo patrimonial isolado, descaracterizando a própria ideia de patrimônio e sua vinculação subjetiva ao contribuinte.

Com efeito, patrimônio é o conjunto de todos os bens, direitos e obrigações de uma pessoa. A variação ou mutação patrimonial pressupõe a comparação do patrimônio, considerado na totalidade dos elementos que o compõem, entre dois momentos distintos, com a consequente verificação de seu acréscimo, diminuição ou estagnação no período. A consideração da unidade do patrimônio do sujeito passivo do imposto de renda, além de inerente à natureza das coisas, é desdobramento lógico do princípio da universalidade, que informa o imposto. Assim, o acréscimo patrimonial verificado num período é o resultado de uma série de operações, não se confundindo com a mera entrada ou ingresso, que no patrimônio pode não permanecer.

A tributação em separado de determinadas operações realizadas pelo contribuinte, sem levar em consideração as demais operações que contribuem para a formação do fato gerador do imposto, num dado período, provoca distorções na realidade, incompatíveis com a essência do imposto de renda, pois permite a incidência do imposto quando não ocorrer acréscimo patrimonial.

Assim, o contribuinte que num determinado período obtenha ganhos líquidos com determinadas operações, mas que no mesmo período apure perdas em outras operações, que por disposição legal, com aquelas não se comunicam, será obrigado a pagar imposto de renda, ainda que a somatória das perdas tenha sido superior aos ganhos obtidos, ou seja, sem que tenha ocorrido acréscimo de seu patrimônio. 
Por outro lado, o regime de imposição segregada de renda desconsidera o caráter pessoal do imposto de renda, não permitindo a progressividade da tributação, nem a sua graduação de acordo com a capacidade contributiva do contribuinte. De fato, a progressividade só pode ser estabelecida considerando-se a totalidade das operações que formam o acréscimo patrimonial real do sujeito passivo. Ou seja, quanto maior o acréscimo patrimonial, decorrente do conjunto de operações realizadas pelo contribuinte, maior a sua capacidade contributiva e, portanto, mais oneroso, progressivamente, o imposto.

Analisando a legislação ordinária que dispõe sobre o imposto de renda, pudemos verificar que, muitas vezes, o legislador ordinário não tem atendido os princípios constitucionais que devem reger a tributação por esse imposto ao instituir concretamente os seus fatos geradores.

Assim, tem sido cobrado o imposto de renda em casos em que não ocorre um verdadeiro acréscimo patrimonial, em desacordo com o conceito de renda delineado em nossa Constituição e no Código Tributário Nacional. É o caso da tributação sobre os ganhos meramente nominais e da renda imputada, por exemplo.

Outrossim, a tributação definitiva ou exclusiva na fonte pelo imposto de renda leva a que sejam abstraídos fatores financeiros negativos que reduzam o montante do acréscimo patrimonial tributável (despesas, custos ou perdas) e as condições pessoais dos contribuintes, em contraste com o imposto de renda apurado pelo regime de declaração, que constitui ônus fiscal personalíssimo por excelência.

Por isso, entendemos que o imposto de renda na fonte deve ser sempre objeto de compensação ou ajuste, a vista da renda total do contribuinte, no período de apuração definido pela lei.

Deste modo, a tributação definitiva ou exclusiva na fonte pelo imposto de renda demonstra-se inconstitucional, por afrontar o caráter pessoal do imposto de renda e o princípio da universalidade, conforme previsto nos arts. $145, \S 1^{\circ}$ e $153, \S 2^{\circ}$, I, da Constituição Federal. Ao invés da tributação sobre a renda e os proventos de qualquer natureza, base de cálculo do imposto de renda, tem-se a tributação sobre a receita dos contribuintes. 
O mesmo ocorre na tributação definitiva, na qual não são considerados os demais resultados positivos e negativos do contribuinte no período de apuração, considerando-se apenas determinados ganhos ou rendimentos específicos do contribuinte. Assim, este pode vir a pagar imposto de renda sem que tenha obtido acréscimo patrimonial no período de apuração, o que conduz à desconsideração do conceito de renda, entendido como acréscimo patrimonial, tal como formulado pelo art. 153, III, da Constituição Federal e definido pelo art. 43 do Código Tributário Nacional.

Além disso, o regime de imposição segregada de renda, por desconsiderar o caráter pessoal do imposto de renda, não permite a progressividade da tributação, nem a sua graduação de acordo com a capacidade contributiva do contribuinte.

Por fim, o regime de tributação segregada da renda pode afrontar o princípio constitucional da igualdade, já que um contribuinte que auferir um determinado acréscimo patrimonial, equivalente ao de outro contribuinte, poderá ser tributado de maneira mais favorável que o outro, em função de que sobre o tipo de rendimento que obteve incide uma alíquota menor.

Ou seja, os dois contribuintes sofrerão uma tributação distinta sem qualquer razão para tal, pois a situação objetiva de ambos é idêntica, ou seja, o acréscimo patrimonial experimentado por ambos é o mesmo. A única diferença será relativa à espécie de acréscimo patrimonial.

Ora, ao tributar de maneira diferente acréscimos patrimoniais idênticos, a lei, na verdade, está discriminando entre espécies de acréscimos patrimoniais, favorecendo uns em detrimento dos outros, em visível afronta ao magno princípio da igualdade.

De tudo o exposto, podemos constatar que o legislador ordinário não tem, em vários casos, atendido aos princípios constitucionais que devem reger a tributação pelo imposto de renda ao instituir concretamente os fatos geradores deste imposto, o que conduz à inconstitucionalidade da legislação instituída em afronta a tais ditames constitucionais. 


\section{REFERÊNCIAS BIBLIOGRÁFICAS}

AMARO, Luciano. Direito tributário brasileiro. 12. ed. São Paulo: Saraiva, 2006.

Imposto de renda: regime jurídico. In: MARTINS, Ives Gandra da Silva (Coord.).

Curso de direito tributário. 9. ed. São Paulo: Saraiva, 2006.

APÊNDICE. São Paulo: Resenha Tributária; CEEU, 1987. p. 413-414. (Caderno de Pesquisas Tributárias, n. 12).

ATALIBA, Geraldo. Hipótese de incidência tributária. 5. ed. São Paulo: Malheiros Ed., 1997.

ÁVILA, Humberto. O princípio da isonomia em matéria tributária. In: TORRES, Heleno Taveira (Coord.). Tratado de direito constitucional tributário: estudos em homenagem a Paulo de Barros Carvalho. São Paulo: Saraiva, 2005.

. Sistema constitucional tributário. São Paulo: Saraiva, 2004.

Teoria dos princípios: da definição à aplicação dos princípios jurídicos. 9. ed. São Paulo: Malheiros Ed., 2009.

BALEEIRO, Aliomar. Direito tributário brasileiro. 10. ed. Rio de Janeiro: Forense, 1985.

Limitações constitucionais ao poder de tributar. 6. ed. Rio de Janeiro: Forense, 1985.

. Uma introdução à ciência das finanças. 14. ed. Rio de Janeiro: Forense, 1987.

BARBOSA, Ruy. Comentários à Constituição Federal brasileira (coligidos e ordenados por Homero Pires). São Paulo: Saraiva, 1933

BARROSO, Luís Roberto; BARCELLOS, Ana Paula de. O começo da história: a nova interpretação constitucional e o papel dos princípios no direito brasileiro. Disponível em: <http://www.camara.rj.gov.br/setores/proc/revistaproc2003/arti_histdirbras.pdf>. Acesso em: 31 mar. 2009..

BASTOS, Celso Ribeiro; MARTINS, Ives Gandra. Comentários à Constituição do Brasil: promulgada em 5 de outubro de 1988. São Paulo: Saraiva, 1988. v. 6, t. 1. 
BECKER, Alfredo Augusto. Teoria geral do direito tributário. 2. ed. São Paulo: Saraiva, 1972.

BIANCO, João Francisco. Transparência fiscal internacional. São Paulo: Dialética, 2007.

BLUM, Walter J.; KALVEN, Jr., Harry. The uneasy case for progressive taxation. 19 U. Chi. L. Rev. 417 (1952). [Texto reproduzido] In: CARON, Paul L.; BURKE, Karen C.; McCOUCH, Grayson M. P. Federal income tax anthology. 2. tir. 2003. Cincinnati, Ohio: Anderson 1997.

BOBBIO, Norberto. Teoria do ordenamento jurídico. 6. ed. Brasília: Ed. da UnB, 1995.

BORGES, José Souto. Isenções tributárias. 2. ed. São Paulo: Sugestões Literárias, 1980.

BOUCHER, Hércules. Estudos de impôsto de renda e lucros imobiliários. Rio de Janeiro: Freitas Bastos, 1953.

BULHÕES, Augusto de. O imposto de renda e a isenção de classes. Revista de Direito Administrativo, Rio de Janeiro, v. 18.

CAMPOS, Francisco. Direito constitucional. Rio de Janeiro: Freitas Bastos, 1956. v. 2.

CANOtilho, J. J. Gomes. Direito constitucional e teoria da Constituição. 4. ed. Coimbra: Almedina, [s.d.].

CANTO, Gilberto de Ulhôa. Imposto sobre a renda e proventos de qualquer natureza. São Paulo: Resenha Tributária; Centro de Estudos de Extensão Universitária, 1986. (Cadernos de Pesquisas Tributárias, v. 11).

CARRAZZA, Roque Antonio. Curso de direito constitucional tributário. 16. ed. São Paulo: Malheiros Ed., 2001.

. Curso de direito constitucional tributário. 14. ed. São Paulo: Malheiros Ed., 2000.

. Curso de direito constitucional tributário. São Paulo: Malheiros Ed., 2004.

Imposto sobre a renda (perfil constitucional e temas específicos). São Paulo:

Malheiros Ed., 2005.

CARVALHOSA, Modesto. Imposto de renda: conceituação no sistema tributário da Carta Constitucional. Revista de Direito Público, São Paulo, ano 1, v. 1, jul./set. 1967. 
CASTRO, Alexandre Barros. Sujeição passiva no imposto sobre a renda. São Paulo: Saraiva, 2004.

CHANCELLOR, Thomas. Imputed income and the ideal income tax. 67 Or. L. Rev. 561 (1988). [Texto reproduzido] In: CARON, Paul L.; BURKE, Karen C.; McCOUCH, Grayson M. P. Federal income tax anthology. 2. tir. 2003. Cincinnati, Ohio: Anderson 1997.

COÊLHO, Sacha Calmon Navarro. Comentários à Constituição de 1988: sistema tributário. Rio de Janeiro: Forense, 1999.

COMPARATO, Fábio Konder. O poder de controle na sociedade anônima. São Paulo: Ed. Revista dos Tribunais, 1976.

CONTI, José Maurício. Princípios tributários da capacidade contributiva e da progressividade. São Paulo: Dialética, 1997.

COSTA, Alcides Jorge. Capacidade contributiva. Revista de Direito Tributário, São Paulo, v. 55, jan./mar. 1991.

- Conceito de renda tributável. In: MARTINS, Ives Gandra da Silva. Imposto de renda: conceito, princípios, comentários. 2. ed. São Paulo: Atlas, 1996.

Imposto sobre a Renda: Aquisição da disponibilidade jurídica ou econômica como seu fato gerador: limite de sua incidência. Revista de Direito Tributário, São Paulo, ano 11, n. 40, abr./jun. 1987.

COSTA, Regina Helena. Princípio da capacidade contributiva. 3. ed. São Paulo: Malheiros Ed., 2003.

DE MITTA, Enrico. O princípio da capacidade contributiva. In: BOTELHO, Roberto Catalano. Princípios e limites da tributação. São Paulo: Quartier Latin, 2005.

DÓRIA, Antônio Roberto Sampaio. Da lei tributária no tempo. São Paulo: Obelisco, 1968. .. Princípios constitucionais tributários e a cláusula due process of law. São Paulo: Ed. Revista dos Tribunais, 1964.

FALCÃO, Amílcar de Araújo. Fato gerador da obrigação tributária. 6. ed. Rio de Janeiro: Forense. 2002. 
FERRAZ, Roberto. Igualdade na tributação: qual o critério que legitima discriminações em matéria fiscal? In: BOTRELHO, Roberto Catalano (Coord.). Princípios e limites da tributação. São Paulo: Quartier Latin, 2005.

FERREIRA, Roberto dos Santos. Crimes contra a ordem tributária. 2. ed. São Paulo: Malheiros Ed., 2002.

FERREIRA FILHO, Manoel Gonçalves. Comentários à constituição brasileira: emenda constitucional $n^{0} 1$, de 17 de outubro de 1969. São Paulo: Saraiva, 1972. v. 1.

Curso de direito constitucional. 28. ed. São Paulo: Saraiva, 2002.

FREEDMAN, Judith. Treatment of capital gains and losses. In: ESSERS, Peter; RIJKERS, Arie (Orgs.) The notion of income from capital. Amsterdam: IBFD, 2005.

GARCIA VIZCAÍNO, Catalina. Derecho tributario. Buenos Aires: Depalma, 1996. t. 1.

GODOY, Norberto J. Impuesto sobre la renta: limites de su incidencia. Revista de Direito Tributário, São Paulo, ano 11, n. 40, abr,/jun. 1987.

GOLDSCHMIDT, Fábio Brun. O princípio do não-confisco no direito tributário. São Paulo: Ed. Revista dos Tribunais, 2003.

GOMES, Orlando. Introdução ao direito civil. 7. ed. Rio de Janeiro: Forense, 1983.

HALL, Robert E.; RABUSHKA, Alvin. The flat tax. (2d ed. 1995). [Texto reproduzido] In: CARON, Paul L.; BURKE, Karen C.; McCOUCH, Grayson M. P. Federal income tax anthology. 2. tir. 2003. Cincinnati, Ohio: Anderson 1997.

HARADA, Kiyoshi. Sistema tributário na Constituição de 1988: tributação progressiva. São Paulo: Saraiva, 1991.

HARTZ, Wilhelm. Interpretação da lei tributária. São Paulo: Resenha Tributária, 1993.

HERRERA MOLINA, Pedro Manuel. Capacidad econômica y sistema fiscal: análisis del ordenamiento español a la luz del Derecho alemán. Madrid; Barcelona: Marcial Pons, 1998.

HOLMES, Kevin. The concept of income: a multi-disciplinary analysis. The Netherlands: IBFD, 2000. 
HUGON, Paul. O imposto: teoria moderna e principais sistemas: o sistema tributário brasileiro. 2. ed. Rio de Janeiro: Financeiras, 1951.

JARACH, Dino. O fato imponível. São Paulo: RT, 1989.

KAVELAARS, Peter. Accrual versus realization. In: ESSERS, Peter; RIJKERS, Arie (Orgs.) The notion of income from capital. Amsterdam: IBFD, 2005.

KORNHAUSER, Marjorie E. The rethoric of the anti-progressive income tax movement: a typical male reaction. 86 Mich. L. Rev. 465 (1987). [Texto reproduzido] In: CARON, Paul L.; BURKE, Karen C.; McCOUCH, Grayson M. P. Federal income tax anthology. 2. tir. 2003. Cincinnati, Ohio: Anderson 1997.

LACOMBE, Américo Masset. Princípios constitucionais tributários. 2. ed. São Paulo: Malheiros Ed., 2000.

LANG, Joachim. The influence of tax principles on the taxation of income from capital. In: ESSERS, Peter; RIJKERS, Arie (Orgs.) The notion of income from capital. Amsterdam: IBFD, 2005.

LEMGRUBER, Andrea. A tributação do capital: o imposto de renda da pessoa jurídica e o imposto sobre operações financeiras. In: ARVATE, Paulo; BIDERMAN, Ciro. Economia do setor público no Brasil. Rio de Janeiro: Elsevier, 2004.

LEONETTI, Carlos Araújo. O imposto sobre a renda como instrumento de justiça social no Brasil. Barueri: Manole, 2003.

MACHADO, Brandão. Breve exame crítico do Art. 43 do CTN. In: MARTINS, Ives Gandra da Silva (Coord.). Imposto de renda: conceito, princípios, comentários. 2. ed. São Paulo: Atlas, 1996.

MACHADO, Hugo de Brito. Curso de direito tributário. 23. ed. São Paulo: Malheiros Ed., 2003.

Imposto sobre a renda e proventos de qualquer natureza. São Paulo: Resenha Tributária; Centro de Estudos de Extensão Universitária, 1986. (Cadernos de Pesquisas Tributárias, v. 11).

Os princípios jurídicos da tributação na Constituição de 1988. 5. ed. São Paulo: Dialética, 2004. 
MARSH, Donald B. The taxation of imputed income. 58 Pol. Sci. Q 514 (1943). [Texto reproduzido] In: CARON, Paul L.; BURKE, Karen C.; McCOUCH, Grayson M. P. Federal income tax anthology. 2. tir. 2003. Cincinnati, Ohio: Anderson 1997.

MARTÍN QUERALT, Juan; LOZANO SERRANO, Carmelo; POVEDA BLANCO, Francisco. Derecho tributario. 5. ed. rev., ampl. y puesta al día. Aranzadi, 2000.

MARTINS, Ives Gandra da Silva. Imposto sobre a renda e proventos de qualquer natureza. São Paulo: Resenha Tributária; Centro de Estudos de Extensão Universitária, 1986. (Cadernos de Pesquisas Tributárias, v. 11).

O princípio da moralidade pública e o fato gerador do imposto sobre a renda. In: MARTINS, Ives Gandra da Silva (Coord.). Imposto de renda: conceito, princípios, comentários. 2. ed. São Paulo: Atlas, 1996.

; BASTOS, Celso Ribeiro. Comentários à Constituição do Brasil: promulgada em 5 de outubro de 1988. São Paulo: Saraiva, 1988. v. 6. t. 1.

MARTINS, Natanael. A indexação monetária nas questões tributárias. In: MARTINS, Ives Gandra da Silva (Coord.). Curso de direito tributário. 4. ed. Belém: CEJUP; Centro de Extensão Universitária, 1995.

MELlO, Celso Antonio Bandeira de. O conteúdo jurídico do princípio da igualdade. 3. ed. São Paulo: Malheiros Ed., 1997.

Curso de direito administrativo. 12. ed. São Paulo: Malheiros Ed., 2000.

MELLO, José Eduardo Soares de Mello. Imposto sobre a renda e proventos de qualquer natureza. São Paulo: Resenha Tributária; Centro de Estudos de Extensão Universitária, 1986. (Cadernos de Pesquisas Tributárias, v. 11).

MILL, J. S. Princípios de economia política. São Paulo: Abril Cultural, 1983. (Coleção "Os Economistas").

MIRANDA, Francisco Cavalcanti Pontes de. Comentários à Constituição de 1967. São Paulo: Ed. Revista dos Tribunais, 1967. t. 2.

Tratado de direito privado. 3. ed. Rio de Janeiro: Borsoi, 1972. t. 50. 
MORAES, Bernardo Ribeiro. O objeto e o fato gerador do imposto de renda. In: MARTINS, Ives Gandra da Silva (Coord.). Imposto de renda: conceito, princípios, comentários. 2. ed. São Paulo: Atlas, 1996.

MÖRSCHBÄCHER, José. Repetição de indébito tributário indireto. 3. ed. São Paulo: Dialética, 1998.

MOSQUERA, Roberto Quiroga. Renda e proventos de qualquer natureza: o imposto e o conceito constitucional. São Paulo: Dialética, 1996.

MUNIZ, Ian de Porto Alegre. Imposto sobre a renda e proventos de qualquer natureza. In: Cadernos de Pesquisas Tributárias, v. 11. São Paulo: Resenha Tributária/Centro de Estudos de Extensão Universitária, 1986.

MUSGRAVE, Richard A. The theory of public finance. New York: McGraw-Hill Book Company, 1959.

.; MUSGRAVE, P. B. Finanças públicas: teoria e prática. São Paulo: EDUSP, 1980.

MUTÉN, Leif. Treatment of capital gains and Losses: a response. In: ESSERS, Peter; RIJKERS, Arie (Orgs.) The notion of income from capital. Amsterdam: IBFD, 2005.

NEUMARK, Fritz. Principios de la imposicion. 2. ed. Madrid: Ministerio de Economia y Hacienda; Instituto de Estudios Fiscales, 1994.

NOGUEIRA, Ruy Barbosa. Curso de direito tributário. 7. ed. São Paulo: Saraiva, 1986.

OLIVEIRA, Ricardo Mariz de. Capacidade contributiva. São Paulo: Resenha Tributária; Centro de Estudos de Extensão Universitária, 1989. (Cadernos de Pesquisas Tributárias, v. 14).

. Fundamentos do Imposto de Renda. São Paulo: Quartier Latin, 2008.

Imposto sobre a renda e proventos de qualquer natureza. São Paulo: Resenha Tributária/Centro de Estudos de Extensão Universitária, 1986. (Cadernos de Pesquisas Tributárias, v. 11).

Princípios fundamentais do imposto de renda. In: SCHOUERI, Luís Eduardo; ZILVETI, Fernando Aurélio. Direito tributário: estudos em homenagem a Brandão Machado. São Paulo: Dialética, 1998. 
OLIVEIRA, Ricardo Mariz de. Variados efeitos fiscais da correção monetária. In: MARTINS, Ives Gandra da Silva (Coord.). Imposto de renda: conceito, princípios, comentários. 2. ed. São Paulo: Atlas, 1996.

ORTEGA, Rafael Calvo. L'interesse legittimo in materia impositiva. Milano: Giuffrè, 1969.

PEDREIRA, José Luiz. Finanças e demonstrações financeiras da companhia: conceitos e fundamentos. Rio de Janeiro: Forense, 1989.

Imposto de renda. Rio de Janeiro: Justec, 1971.

Imposto sobre a Renda. Pessoas Jurídicas. Rio de Janeiro: ADCOAS JUSTEC, 1979.

PENTEADO, João Caio Goulart. Capacidade contributiva. São Paulo: Centro de Estudos de Extensão Universitária; Resenha Tributária, 1989. (Caderno de Pesquisas Tributárias, v. 14).

PIGOU, A. C. A study in public finance. 3d ed. London: Macmillan, 1951.

PONTES, Helenilson Cunha. O princípio da proporcionalidade e o direito tributário. São Paulo: Dialética, 2000.

QUEIROZ, Mary Elbe de. Imposto sobre a renda e proventos de qualquer natureza: princípios, conceitos, regra-matriz de incidência, mínimo existencial, retenção na fonte, renda transnacional, lançamento, apreciações críticas. Barueri: Manole, 2004.

REALE, Miguel. Lições preliminares de direito. São Paulo: Saraiva, 1987.

Lições preliminares de direito. 27. ed. São Paulo: Saraiva, 2009.

ROTHMANN, Gerd Willi. Bitributação internacional. In: FRANÇA, Rubens Limongi (Org.). Enciclopédia Saraiva do Direito. São Paulo: Saraiva, 1978. v. 11, p. 447-460.

O princípio da legalidade tributária. In: Temas fundamentais do direito tributário Atual. Belém: CEJUP, 1983.

ROXAN, Ian. Imputed income (including deductible costs). In: ESSERS, Peter; RIJKERS, Arie (Orgs.) The notion of income from capital. Amsterdam: IBFD, 2005. 
SCHOUERI, Luís Eduardo. Discriminação de competências e competência residual. In: SCHOUERI, Luís Eduardo; ZILVETI, Fernando Aurélio. Direito tributário: estudos em homenagem a Brandão Machado. São Paulo: Dialética, 1998.

Normas tributárias indutoras e intervenção econômica. Rio de Janeiro: Forense, 2005 .

SELIGMAN, Edwin R. Progressive taxation in theory and practice. $2 \mathrm{~d}$ ed. Princeton, N. J.: American Economic Association; Princeton University Press, 1908.

SILVA, José Afonso da. Aplicabilidade das normas constitucionais. 7. ed. São Paulo: Malheiros Ed., 2008.

Curso de direito constitucional positivo. 5. ed. São Paulo: Ed. Revista dos Tribunais, 1989.

. Sistema tributário nacional. São Paulo: Ed. Revista dos Tribunais, 1975.

SIMONS, Henry. Personal income taxation: the definition of income as a problem of fiscal policy. Chicago: University of Chigaco Press, 1938.

SMITH, Adam. A riqueza das nações. São Paulo: Martins Fontes, 2003.

SOUSA, Rubens Gomes de. Compêndio de legislação tributária. 2. ed. Rio de Janeiro: Edições Financeiras, 1954.

- Imposto de Renda. Suplemento à 2.ed. do Compêndio de Legislação Tributária para atualização do Decreto $n^{\circ}$ 36.773, de 13-1-55. Rio de Janeiro: Edições Financeiras, [s.d.].

Pareceres - 3. Imposto de Renda. Edição póstuma. São Paulo: Resenha Tributária; Instituto Brasileiro de Estudos Tributários, 1976.

Reforma de discriminação de rendas (anteprojeto). Rio de Janeiro: Fundação Getúlio Vargas, 1965.

SOUZA, Antonio Carlos Garcia de. Imposto sobre a renda e proventos de qualquer natureza. São Paulo: Resenha Tributária; Centro de Estudos de Extensão Universitária, 1986. (Cadernos de Pesquisas Tributárias, v. 11). 
SUPREMO TRIBUNAL FEDERAL. Disponível em: <http://www.stf.gov.br/juris.html>. Acesso em: 02 jun. 2009

TILBERY, Henry. Comentários ao Código Tributário Nacional. In: MARTINS, Ives Gandra da Silva (Coord.). São Paulo: Saraiva, 1998.

O novo imposto de renda no Brasil: comentário à Lei 7.713/88 ajustado aos novos métodos de atualização monetária. São Paulo: IOB, 1989.

A tributação dos ganhos de capital. São Paulo: Resenha Tributária; Instituto Brasileiro de Direito Tributário, 1977.

TIPKE, Klaus. A necessidade de igualdade na execução das leis tributárias. In: SCHOUERI, Luís Eduardo (Coord.). Direito tributário: homenagem a Alcides Jorge Costa. São Paulo: Quartier Latin, 2003. v. 1.

. Sobre a unidade da ordem jurídica tributária. In: SCHOUERI, Luís Eduardo;

ZILVETI, Fernando Aurélio (Coords.). Direito tributário: estudos em homenagem a Brandão Machado. São Paulo: Dialética, 1998.

; YAMASHITA, Douglas. Justiça fiscal e princípio da capacidade contributiva. São Paulo: Malheiros Ed., 2002.

TORRES, Ricardo Lobo. Curso de direito financeiro e tributário. 16. ed. Rio de Janeiro: Renovar, 2009.

Normas de interpretação e integração no direito tributário. 3. ed. Rio de Janeiro: Renovar, 2000.

UCKMAR, Victor. Princípios comuns de direito constitucional tributário. 2. ed. São Paulo: Malheiros Ed., 1999.

URUGUAI reinstitui IR para pessoa física após 40 anos. Valor Econômico, São Paulo, 4 de jul. de 2007. p. A11.

VANONI, Ezio. Natureza e interpretação das leis tributárias. Trad. de Rubens Gomes de Souza. Rio de Janeiro: Edições Financeiras, [s.d.].

XAVIER, Alberto. Direito tributário internacional do Brasil: tributação das operações internacionais. 5. ed. Rio de Janeiro: Forense, 2002. 
XAVIER, Alberto. Estudos de direito tributário, n. 20. São Paulo: Resenha Tributária, 1991.

Os princípios da legalidade e da tipicidade da tributação. São Paulo: Ed. Revista dos Tribunais, 1978.

ZILVETI, Fernando Aurelio. O princípio da realização da renda. In: SCHOUERI, Luís Eduardo (Coord.). Direito tributário: homenagem a Alcides Jorge Costa. São Paulo: Quartier Latin, 2003. v. 1.

Princípios de direito tributário e capacidade contributiva. São Paulo: Quartier Latin, 2004.

- Progressividade, justiça social e capacidade contributiva. Revista Dialética de Direito Tributário, São Paulo, n. 76, p. 27-32, jan. 2002.

; COELHO, Mônica Pereira. Ensaio sobre o princípio do não-confisco. Revista Direito Tributário Atual, São Paulo, n. 20, 2006. 